\title{
Reasons and Solutions for the Prevalence of Psychology Diseases Among Young People in China
}

\author{
Yutong Chen ${ }^{1, *}$
}

${ }^{1}$ St.Juse's Academy, Mississauga, ON, L5N 2M6, Canada

1264628652@qq.com

\begin{abstract}
In today's China, there are more and more adolescent patients with psychological diseases. The Chinese government has also promulgated many policies to deal with this, and all schools are required to set up professional psychological consultation rooms and be equipped with professional counselors. This article uses questionnaire surveys, interviews and other methods to study the theme of "why are there more and more young people with psychological diseases". This research mainly obtains data from the "Annual Report on China's National Mental Health Status", and analyzes the current psychological health of young people in China. Through investigation and research, this article finally draws two reasons for its occurrence. The first is because of the huge competitive pressure under China's rigid education, and the second is because of the rapid development of the times and the wrong use of new media by some young people. This paper hopes that China's future development of psychological health can be implemented.
\end{abstract}

Keywords: Psychological disease, Analysis of reasons, Countermeasures

\section{INTRODUCTION}

In recent years, the frequency of Psychological Disease among Chinese young people aged 10-20 has increased, especially in the early adulthood (around 1820 years old) college freshmen are in a more problematic stage. China comprehensively implements and strengthens youth mental health work, and supports the overall work with professional scientific management. Recently, the General Office of the Ministry of Education issued the "Notice on Strengthening the Management of Student Mental Health" and mentioned the need to set up public compulsory psychology health courses in colleges and universities in China, and the need to include mental health courses by textbooks in primary and secondary schools. Contemporary teenagers between the ages of 10 and 20 are faced with the dual pressure of the high school entrance examination and the college entrance examination. If they cannot be resolved in time, they will have very bad consequences. This article mainly investigates and discusses the causes and solutions of the prevalence of mental illness in contemporary Chinese adolescents aged 10 to 20through the form of data queries and questionnaires. And combined with the Ministry of Education's regulations and restrictions on minors to take some supplements to this article. Hope this article can play a positive role in the development of China's mental health, and let Chinese teenagers get the relief of their psychological pressure in time.

\section{THE PSYCHOLOGICAL DISEASE IN CHINESE YOUNG PEOPLE}

Through my browsing the web pages on the Internet and researching some online articles, I found that on the Internet, people think that Chinese teenagers have more and some of the psychological problems that actually appear in teenagers. This research depression and anxiety disorders for analysis. Depression is a well-known mental illness, and anxiety is also caused by the pressure of Chinese teenagers in their studies and life[6].

\subsection{Depression}

Depressive disorder is the most painful and longest period that we may need to experience in life. This disease will obliterate our will and make our life negative, difficult to get through and hopeless. Even when the condition is serious, we lose the motivation to live, thinking that the disease of depression cannot be cured, which leads to the idea of "this world is not worth it" and the act of committing suicide. But after a long period of research by psychologists, it has been found that depression can be completely cured and recovered. Of 
course, the specific conditions vary from person to person. Although scientists have not yet developed a treatment method that can be immediate and has few side effects, there are some treatment methods that have been developed (such as medication, psychological counseling, etc.) that can still be tried. At present, people generally believe that the origin of depression in young people is caused by excessive stress and interpersonal relationships, which will be analyzed in detail later[7].

\subsection{Anxiety}

At present, there is widespread anxiety among young people. This emotion is mostly caused by the inferiority caused by the difference between their actual situation and the perfect image in this society. When this emotion is gradually amplified, it will gradually become a distressing anxiety disorder accompanied by very low self-esteem. Anxiety is a kind of emotion that everyone will have in life, but if we cannot express it in time, it may lead to excessive inferiority and negative emotion backlog which leads to unconfidence in ourselves and thinks that we are not good enough and not worthy of it. This disease is caused more by a sense of inequity and gap after using social media. When their own bad situation is in contrast with the good lives of others on the Internet, contemporary young people are extremely prone to feelings of imbalance and jealousy. Another major cause of anxiety is the pressure brought by the original family and work or study occasions. When everyone around me is struggling to make progress, I am afraid that I may be abandoned by this society and become a waste because of not working hard enough. Therefore, they choose to stay up late and work overtime and study constantly in order to keep up with the pace of the times, but at the same time, high-intensity competition and some deformed comparisons will lead to bad psychology.

\section{CAUSE ANALYSIS}

Through some of my surveys on the Internet and some informal interviews offline. I have summarized two main reasons. The first one in the endless competitive pressure generated by China's rigid education background. Chinese young people will face two big exams, one is the middle school entrance examination for junior high school, and the other is the college entrance examination which can almost determine the fate of life. If there is a failed performance in one of these two exams, the road to success will have more obstacles. The second reason I think is that modern technology is becoming more and more developed, and information dissemination is becoming faster and faster. When teenagers do not have their own judgment, they will lose themselves because of some false things on the Internet or inadvertently reveal their privacy on the Internet.

\subsection{Competitive Pressure}

Behind the rapid development of China's economy, the problem we need to face is the increasing pressure of competition with the times. As the saying goes, young people are the flowers of the motherland and the hope for future development. Therefore, China's traditional rigid education has affected people from generation to generation. At the beginning, everyone worked hard to get out of poverty together. But with the development of the times, this way of education seems to have become counterproductive. The current situation of students in primary and secondary schools every week is endless tuition classes and extracurricular classes, endless homework, and overwhelming competitive pressure. As a result, in the hearts of Chinese primary and middle school students, seeking knowledge has become a very painful thing. There was a piece of news that spread through the people in China. "The second-ranked student in a school was dissatisfied that the first-ranked student performed better than him, so he killed the first-ranked student so that he was the first." Although the reason for this news was later confirmed as a rumor, it is worth thinking about why such a rumor appeared. This is also closely related to China's traditional education methods. In the local schools where the incident occurred, slogans such as "Learn to the death if you don't die" and "Improve one point will surpass thousands of people" were hung everywhere in the local schools. Even the local maternity hospitals are named "doctoral beds" and "master beds". Chinese children seem to have been instilled since childhood the idea that if they don't work hard, they will be abandoned by the world. Therefore, from school to work, most of the young people in China are constantly "desiring". They consume their health to gain money and status. In contemporary China, only the people and things at the top of the pyramid are often paid attention to, but it is overlooked that the reason why it stands at the top is because there are countless ordinary people and failures underneath it. According to a survey conducted by the Institute of Psychology, Chinese Academy of Sciences, the sleep duration of contemporary adolescents has shown an increasingly serious trend compared to the decline in 2009 [3]. Contemporary teenagers are overspending their sleep time to participate in this unhealthy competition, which is a choice that has only disadvantages for their body and mind. 


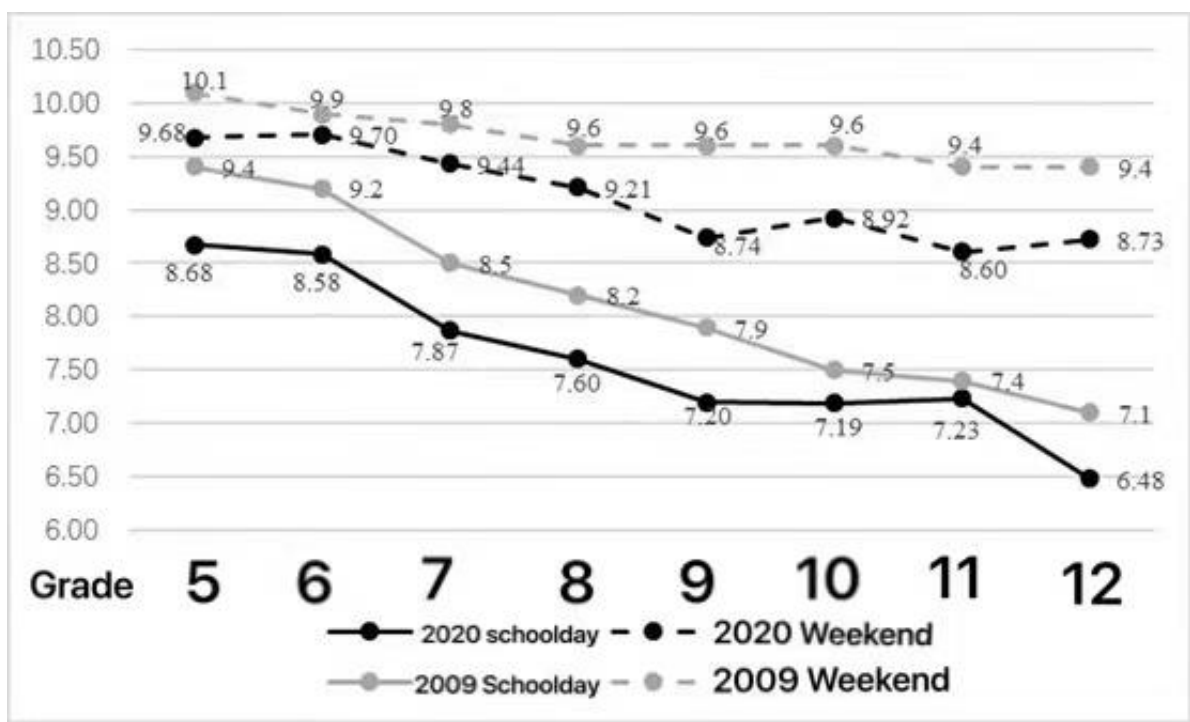

Figure 1 Comparison of sleep time of adolescents in 2009 and 2020

\subsection{Use of the Internet and New Media}

According to surveys, the use of some new media can also cause contemporary young people to suffer from psychological illness. First of all, for younger children, when they come into contact with new media, they will be attracted to all kinds of things and lose their judgment. The excessive use of new media by young people can also lead to addictive behaviors, thereby reducing psychological defenses and increasing the chance of mental illness. When adolescents see some of the more "extravagant" lives shared by others and the "perfect" appearance of some people on the Internet, they will also have a certain sense of gap, which will lead to inferiority. But everything has two sides. Some children are not recognized in the real world, but they can shine on the Internet. However, the over-reliance of adolescents on the online world brings more negative effects, such as decreased academic performance and interest, myopia, depression, and anxiety. At the same time, the transparency of this era has also caused the emergence of cyber violence. People's privacy began to become transparent, and people put on "The emperor's new clothes". In today's society, personal information can be easily obtained in many ways. For example, the sale of scalpers, "human research" on the Internet, and so on. People's awareness of their own privacy protection is not strong enough, and it is easy to reveal their personal privacy on some social platforms. Thereby causing leakage and misappropriation by others. Sometimes a netizen made up some things out of context on the Internet, causing the person concerned to be cast aside by everyone. It is possible that the client did not do this, but because of the fragmentation of our lives, we easily believed the report and attacked the client personally. The endurance of adolescents has not yet developed very well. After being subjected to constant verbal attacks or even a "manpower search" for their true identity, they are prone to psychological illness or choice after the impact on their real swollen life suicide. "No snowflake is innocent in an avalanche." We are likely to be one of the driving forces behind this chilling incident[2]. On the one hand, the emergence of the Internet and new media has made our lives more convenient, but at the same time, we have to bear the disadvantages of over-development.

\section{SOLUTIONS}

\subsection{Medical Treatment}

Drug therapy is the most effective and direct treatment found so far, but relatively speaking, it has the largest side effects. "In March 2019, the US FDA approved the first new rapid antidepressant drug Spravato (esketamine, S-ketamine) nasal spray in 30 years for the treatment of patients with refractory depression. Johnson \& Johnson's Janssen Pharmaceuticals said, this is the first and currently only approved drug that has been proven to relieve depression symptoms within 24 hours. Clinical research data shows that the effect can be seen 4 hours after the first administration."[1] On July 28, the top international scientific journal "Nature" also published an article titled "Structural basis of ketamine acting on human NMDA receptors", which explains why ketamine can be used to treat depression and other problems. This research has also laid the foundation for the development of new antidepressant targeted drugs, and the team of related drugs around the world has also benefited. Whether in China or overseas, everyone is looking for the easiest and fastest way to cure various mental illnesses[1].

\subsection{Psychological Intervention}

In recent years, China has gradually begun to carry out a series of actions for the treatment and intervention of psychological diseases. For example, in November 2018, the National Health Commission, the Central Political and Legal Affairs Commission, the Central 
Propaganda Department and other 10 departments jointly issued the "National Psychological Service System Construction Pilot Work Plan"; in July 2019, the State Council issued the "Implementation of the Healthy China Action Plan" and "Healthy China Action (2019-2030)". Some universities, primary and secondary schools in my country have begun to set up psychological counseling rooms one after another and hire professional psychological counselors to file the overall information of students and give regular lectures and publicity activities to popularize the psychological knowledge of students. When a problem is found, it is necessary to promptly enlighten and intervene. Regarding the current convenience and satisfaction of psychological counseling in society and on campus, the survey in 2020 learned that

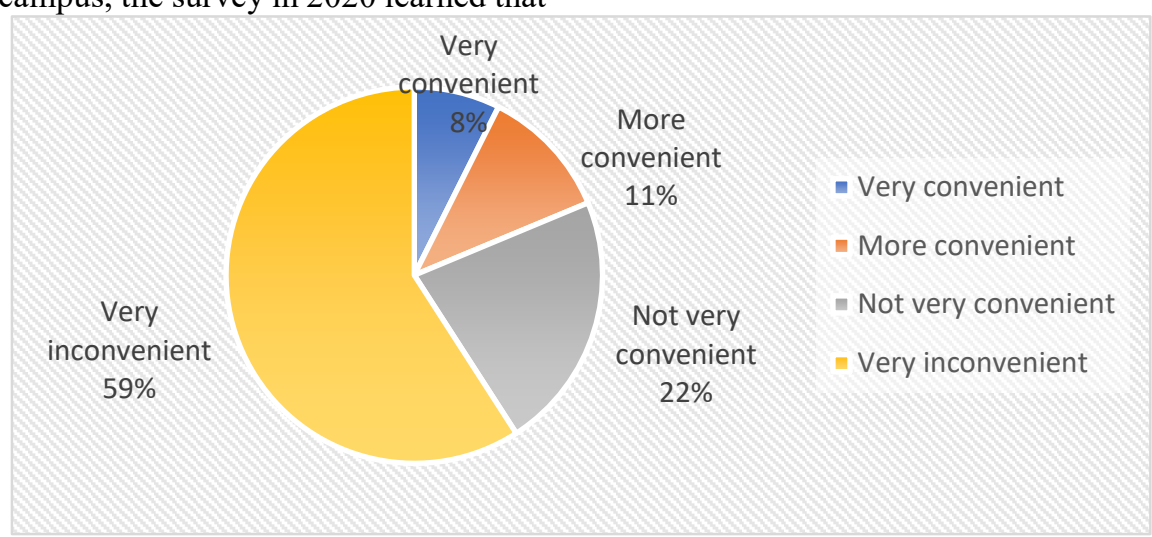

Figure 2 Awareness of the convenience of obtaining mental health services

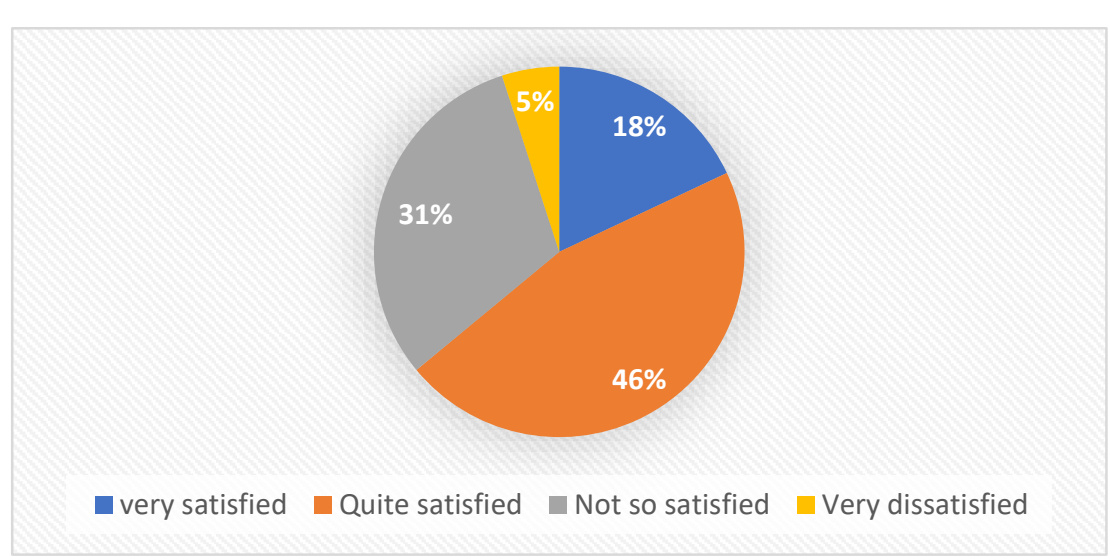

Figure 3 Satisfaction with mental health services the total number of people who believe that my country's mental health counseling services are "very convenient" and "more convenient" accounted for only $38 \%$. Consultation satisfaction also only accounted for $40.1 \%[3]$. This also fully reflects that China has a long journey towards mental health. The first step is to improve the overall professional level of the consulting team and the research team so as to increase the public's satisfaction with the consulting service and truly intervene in the disease. And conduct some publicity lectures in various places to popularize professional knowledge and eliminate the prejudice and misunderstanding of the people about the psychological disease from the root[4].

\subsection{Strengthen Network Environment Control}

In order to prevent minors from indulging in online games and reduce the impact of some violence on the Internet on minors, the state has also promulgated some corresponding policies. One of them is that China currently has a series of policies for minors to use the Internet[5]. Among them, the latest "Notice on Further Strict Management and Practically Preventing Minors from Indulging in Online Games" stipulates those minors can only be used on Fridays and Saturdays., Sunday 20: 00-21: 00 online games. This also prevents most minors from becoming addicted to online games, but Chinese teenagers have various methods for evading policies. One of the simplest is to use the elder's ID card for real-name authentication and borrow someone else's account. In addition, for some online violent behaviors, studies have shown that young people will imitate after too much exposure to some violent videos or pictures. Therefore, a lot of software has also introduced a youth model for a preliminary prevention. However. there are many loopholes in this policy that need to be filled. For example, when young people download software, they also make self-selection. Their curiosity will drive them to explore 
options that can bring them excitement. Including a "blue whale game" that appeared a few years ago, the master behind it step by step manipulated the psychology of these young people and made them commit suicide. From beginning to end, the whole thing was carried out on the Internet, but the regulators of the network environment did not find out in time, but began to investigate and resist when the incident became more serious. While we are enjoying the dividends brought by the development of science and technology, we also hope that the government can strengthen the control of the network environment and create a safe network environment for young people.

\section{CONCLUSION}

In recent years, people's lives have gradually become richer. After material life is fully satisfied, people have begun to care about their spiritual needs. When people's spiritual needs are not met, they are prone to mental illness. The psychological diseases I studied in this article are depression and anxiety. Because of the huge and ubiquitous competitive pressure in contemporary Chinese society, Chinese teenagers are prone to anxiety, and in severe cases, they will develop anxiety. The above conclusion shows that China's rigid education and parents' high expectations are actually the main culprits of these pressures. The high expectations of teenagers can cause them to lose sight of what they really like and what they want. what. But if there are professional people to provide timely psychological counseling and guidance to these young people, it is possible to gradually recover. However, due to China's previous lack of action and awareness of psychological health, this anxiety gradually intensified and evolved into depression. There is another reason for depression and anxiety. In the rapid development of the contemporary Chinese digital age, everyone's information is basically made public. When an immature teenager travels on the Internet, it is easy to be confused and deceived by some false information on the Internet, and easily expose his privacy on the Internet. When we are on the Internet, careless words and deeds can easily attract some criticism, and things can easily spread through the Internet. Some teenagers cannot accept the criticism (also known as "Internet violence") on the Internet because they are not very accepted in their hearts, so they choose to commit suicide. The Chinese government is also taking actions to enhance the psychological health of Chinese youths, offering psychological health courses in various schools, and requiring the deployment of professional psychological consultation rooms and psychological counselors. Regular lectures on psychological health are given in the school, and the teachers in the school pay more attention to the physical and mental health of the students. Some families have also provided psychological counseling to their children and have regular heart-to-heart talks. Intervene the occurrence of mental illness through better mental health. If you find that you have a psychological problem, you should treat it in time. Early detection, early treatment, early recovery.

\section{REFERENCES}

[1] Nianmiao Zhang. (2021). Depression research, "fine and interesting". Xinmin Weekly (30), 68-71. doi:CNKI:SUN:XMZK.0.2021-30-022.

[2] Yongchang Zhang \& Hao Yu. (2021). Research progress on social media and adolescent mental health. Journal of Jining Medical College (04), 278280+285. doi:CNKI:SUN:JNYY.0.2021-04-012.

[3] Xiaolan Fu \& Kan Zhang. (2021). The Blue Book of Mental Health: Report on national mental health development in China (2019-2021)

[4] Silhouette Wang. (2012). The mechanism and treatment of psychological illness. Shenzhou (05), 44+46. doi:CNKI:SUN:SHZH.0.2012-05-037.

[5] Zhiyan Chen (2021-04-15). Adolescence is a key stage in the development of mental illness. Journal of Social Sciences, 004.

[6] Addis, M. E., \& Jacobson, N. S. (1996). Reasons for depression and the process and outcome of cognitive-behavioral psychotherapies. Journal of Consulting and Clinical Psychology, 64(6), 14171424. https://doi.org/10.1037/0022-006X.64.6.1417

[7] Aaron T. Beck, M.D., Brad A. Alford ( 2009 ) Depression: Causes and Treatment, University of Pennsylvania Press 